\title{
STORAGE AND HYDROLYSIS OF SEAWATER SAMPLES FOR INORGANIC CARBON ISOTOPE ANALYSIS
}

\author{
Charlotte L Bryant ${ }^{1,2} \cdot$ Sian F Henley ${ }^{3}$ Callum Murray $^{1}$ • Raja S Ganeshram ${ }^{3}$ ' Richard Shanks ${ }^{4}$ \\ ABSTRACT. Preservation of seawater samples was tested for total inorganic carbon $\left(\Sigma \mathrm{CO}_{2}\right)$, stable carbon isotope $\left(\delta^{13} \mathrm{C}\right)$, \\ and radiocarbon $\left({ }^{14} \mathrm{C}\right)$ applications using foil bags and storage by refrigeration and freezing. The aim was to preserve repre- \\ sentative samples with minimal storage effects but without using toxic methods such as mercuric chloride poisoning. Hydrol- \\ ysis of samples to $\mathrm{CO}_{2}$ was based on existing methods. Results of IAEA-C2 standard used with deionized water stored in the \\ foil bags showed complete reaction yields, ${ }^{14} \mathrm{C}$ results within $2 \sigma$ of the consensus value, and $\delta^{13} \mathrm{C}$ that were internally con- \\ sistent, indicating that there were no procedural effects associated with the foil bags. ${ }^{14} \mathrm{C}$ results were statistically indistin- \\ guishable across the storage times, for frozen and refrigerated seawater samples from a coastal site, Elie Ness, Fife, UK. The \\ scatter of $\Sigma \mathrm{CO}_{2}$ concentrations and $\delta^{13} \mathrm{C}$ was within scatter observed in other studies for lake- and seawater samples preserved \\ by acidification or using mercuric chloride. However, both $\Sigma \mathrm{CO}_{2}$ and $\delta^{13} \mathrm{C}$ were less variable for frozen samples compared \\ with refrigerated samples. The foil bags are lighter, safer to transport, and similar in cost to glass bottles and allow sample col- \\ lection in the field and transfer to the hydrolysis vessel without exposure of the sample to atmosphere. Storage of seawater \\ samples in the foil bags was considered a reliable, alternative method to poisoning for $\Sigma \mathrm{CO}_{2}, \delta^{13} \mathrm{C}$, and ${ }^{14} \mathrm{C}$, and freezing the \\ samples is recommended for storage time beyond a week.
}

\section{INTRODUCTION}

Carbon isotope measurements of inorganic carbon in freshwater and marine samples are used for examining hydrological patterns, carbon sources and cycling, and the relationship between the atmosphere and aquatic environment. Preservation of seawater samples for carbon isotope analysis of inorganic carbon should ensure that the original carbon isotope ratios and total inorganic carbon $\left(\Sigma \mathrm{CO}_{2}\right)$ concentrations from the sample collected in the field are retained through storage, laboratory hydrolysis of the sample, and final analysis. Early accelerator mass spectrometer (AMS) measurements of ${ }^{14} \mathrm{C}$ in seawater dissolved inorganic carbon (e.g. Bard et al. 1987; Schlosser et al. 1988) and subsequent large-scale ${ }^{14} \mathrm{C}$ analytical programs such as the World Ocean Circulation Experiment (WOCE, McNichol et al. 1994) involved sample preservation with mercuric chloride. While this compound inhibits biological activity and reliably preserves the carbon isotope ratios and concentrations of inorganic carbon even after long-term storage (McNichol et al. 1994), its toxicity and potential hazard to the environment have stimulated the search for alternative preservation methods. Hydrated copper sulfate has been used to preserve water samples (Taipale and Sonninen 2009), but speciation and precipitation of copper with carbon components in the samples produced variable concentration data and $\delta^{13} \mathrm{C}$. Filtration via $0.2-\mu \mathrm{m}$ filters and storage in the dark was sufficient to avoid changes in concentration and $\delta^{13} \mathrm{C}$ in streamwater samples (Doctor et al. 2008). However, the filtration, particularly if carried out in the atmosphere, could have adverse effects on the ${ }^{14} \mathrm{C}$. Acidification of water samples with phosphoric acid in the field inhibits biological activity and also hydrolyzes the sample to carbon dioxide $\left(\mathrm{CO}_{2}\right)$, which is required for preparing samples for carbon isotope analysis. Lake-water samples stored in 12-mL septa-covered Exetainers ${ }^{\circledR}$ were acidified with phosphoric acid in the field and retained their original $\delta^{13} \mathrm{C}$ values after 6 months of storage (Taipale and Sonninen 2009). Where both $\delta^{13} \mathrm{C}$ and ${ }^{14} \mathrm{C}$ are to be analyzed, a larger volume of sam-

\footnotetext{
${ }^{1}$ NERC Radiocarbon Facility, Scottish Universities Environmental Research Centre (SUERC), Scottish Enterprise Technology Park, Rankine Avenue, East Kilbride G75 0QF, United Kingdom.

${ }^{2}$ Corresponding author. Email: charlotte.bryant@glasgow.ac.uk.

${ }^{3}$ School of Geosciences, King’s Buildings, University of Edinburgh, West Mains Road, Edinburgh EH9 3JW, United Kingdom.

${ }^{4}$ AMS Laboratory, SUERC, Rankine Avenue, East Kilbride G75 0QF, United Kingdom.
}

(C) 2013 by the Arizona Board of Regents on behalf of the University of Arizona

Proceedings of the 21st International Radiocarbon Conference edited by A J T Jull \& C Hatté

RADIOCARBON, Vol 55, Nr 2-3, 2013, p 401-409 


\section{L Bryant et al.}

ple is likely to be required and a greater potential for leaks and/or exchange with the atmosphere might be expected for larger samples stored in gaseous form. Hydrolysis with phosphoric acid in evacuated glass reaction vessels is a widely used laboratory method for preparing preserved seawater samples for ${ }^{14} \mathrm{C}$ analysis (Bard et al. 1987; McNichol et al. 1994). The method could also be used for preserving water samples, but this would be impractical in the field and poses a significant risk of contamination by air during transport of the evacuated vessel.

We have used foil bags (FlexFoil PLUS, SKC Inc., USA) successfully for $\mathrm{CO}_{2}$ and methane ${ }^{14} \mathrm{C}$ field sampling (Garnett et al. 2012) and the manufacturer reports indicate that the materials used to make the bags are highly stable for environmental gas sampling (http://www.skcinc.com/prod/26201.asp\#233). We present results of tests to determine whether these bags are also suitable for the collection and storage of seawater samples for inorganic carbon isotope analysis. The foil bags are lighter, safer to transport, and similar in cost to glass bottles and allow sample collection in the field without exposure of the sample to atmosphere. Details are also provided of our procedure to transfer the sample to the reaction vessel, also without exposing the sample to atmosphere, and subsequent acid hydrolysis.

\section{METHODS}

\section{Field Sampling and Sample Storage}

One-liter capacity foil bags (Figure 1, FlexFoil PLUS), composed of 4 layers (polypropylene, polyethylene, aluminium foil, and polyethylene), were adapted to allow easy introduction of liquid sample, by removing the stainless steel fitting and the rubber septum, leaving only a stainless steel tube. Approximately $10 \mathrm{~cm}$ length of Tygon ${ }^{\circledR}$ tubing (cat no-R6303; $10 \mathrm{~mm}$ OD, $7 \mathrm{~mm}$ ID) was attached to the tube. The sample bags were flushed several times with nitrogen gas and a plastic clip applied across the Tygon tubing to seal the bag from the atmosphere.

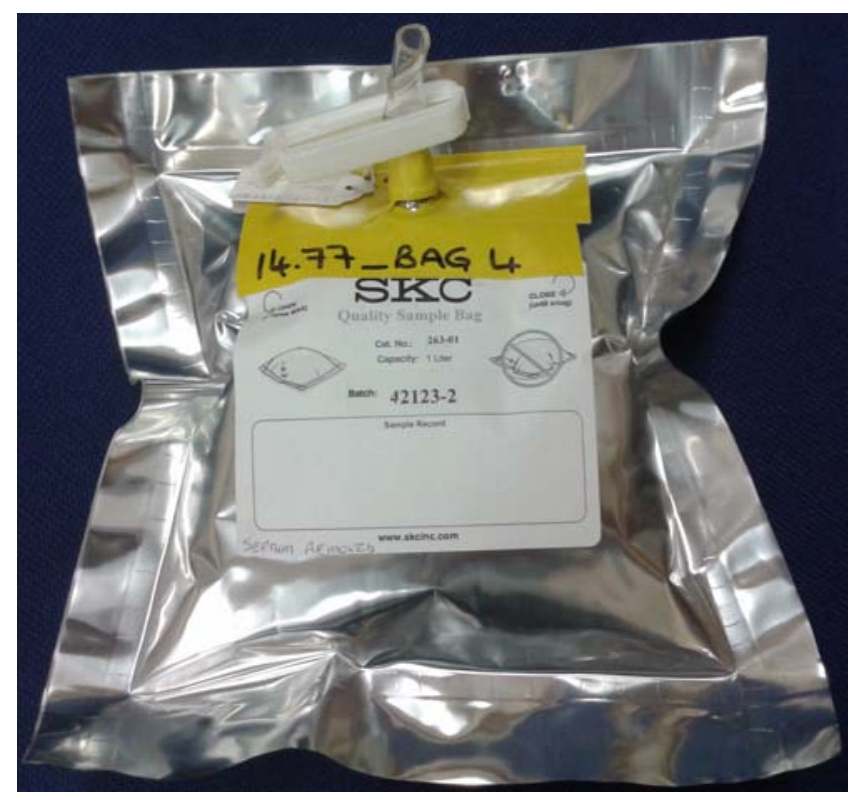

Figure 1 Foil bag (FlexFoil PLUS, SKC Inc.) showing adapted connection for sample collection. 
Seawater samples were collected from Elie Ness, Fife, UK, 56 ${ }^{\circ} 11^{\prime} 0624^{\prime \prime} \mathrm{N} 2^{\circ} 48^{\prime} 7938^{\prime \prime} \mathrm{W}$ (UK Ordnance Survey Grid Ref. NT497993), a coastal site that was sampled within an hour of high tide on 25 August 2011, during which the water depth at the site was $4.5 \mathrm{~m}$, temperature was $13.7^{\circ} \mathrm{C}$, and salinity was 30.4 PSU (YSI-500 multiparameter meter). Samples were collected at $3 \mathrm{~m}$ water depth, using a Niskin bottle sampler. Prior to sample collection, each foil bag was sample-rinsed by attaching the Tygon ${ }^{\circledR}$ tubing to the Niskin sampler tap, removing the clip on the Tygon tubing and allowing approximately $50 \mathrm{~mL}$ of water to enter the bag, and then allowing the bag to drain. The foil bag was then filled to $\sim 500 \mathrm{~mL}$ (half the bag capacity) and then, held with the outlet pointing upwards, the bag was gently squeezed so that the Tygon tubing remained water-filled before reapplying the clip, to secure the sample and ensure no air was trapped in the sample bag. Triplicate seawater samples were collected for hydrolysis following storage for 1,4 , and 8 days (one of which, for technical reasons, had to be hydrolyzed at 11 days) and 33 days at $+4{ }^{\circ} \mathrm{C}$, and 8 and 33 days at $-10{ }^{\circ} \mathrm{C}$. The storage times were chosen to reflect typical sample storage duration between field sampling and laboratory processing.

A further 2 samples were collected and added directly to evacuated glass hydrolysis vessels (details below) in the field, followed by hydrolysis with $85 \%$ phosphoric acid (Fischer, Analytical Grade) within minutes of collecting the sample. The evolved $\mathrm{CO}_{2}$ was then isolated the following day in the laboratory.

The foil bags were used to store samples from Ryder Bay, western Antarctic Peninsula $\left(67^{\circ} 34.200^{\prime} \mathrm{S}, 68^{\circ} 13.500^{\prime} \mathrm{W}\right)$, collected at a water depth of $500 \mathrm{~m}$ on 2 December 2009 (RaTS 901) and 12 February 2010 (RaTS 923). These samples were used to compare results following longerterm frozen storage and identify effects of subsampling seawater samples from foil bags after defrosting and refreezing. Foil bag samples were frozen for 11-13 months, defrosted, hydrolyzed (130-150 mL sample volumes) and $\mathrm{CO}_{2}$ collected, and then refrozen for a further 10 months before defrosting and hydrolysis to obtain a further aliquot of $\mathrm{CO}_{2}$.

\section{Preparation of Hydrolysis Vessels}

Hydrolysis vessels consist of a 1000-mL round-bottom flask with a main neck opening (Quikfit ${ }^{\circledR}$ 14/ 29) and a side arm opening (14/23). Above the main neck, an attachment with a second side arm opening and a 50-mL dropper funnel with tap (Quikfit D62/50GR with 19/26 socket) is attached so that phosphoric acid can be added to the vessel without opening the vessel to air (by leaving $\sim \mathrm{cm}^{3}$ of acid in the funnel). A valve with glass connectors is attached to each side arm. The vessel is connected to the vacuum line via one of these connectors, using Cajon and Viton O-ring fittings ( $1 / 44^{\prime \prime}$ SS4-UT-6) and metal flexi-tubing. The other connector (made in-house with 14/23 socket and rotaflo tap $5 \mathrm{~mm}$ ID, $7 \mathrm{~mm}$ OD) has a glass nozzle reaching almost to the base of the hydrolysis vessel and is used to add the foil bag samples to the vessel, by attachment of Tygon tubing from the bag to the glass connector. This connector is also used during hydrolysis, to pass helium gas through the sample and acid, to ensure all $\mathrm{CO}_{2}$ is driven out of solution. Hydrolysis vessels are evacuated to at least $5 \times 10^{-3}$ mbar the previous day and checked for leaks after several hours.

\section{Hydrolysis of Samples}

The foil bags are attached to the hydrolysis vessels by the Tygon tubing from the foil bag and a further length of Tygon tubing (to enable the bag to be placed onto a balance) onto the glass side arm connector and valve. The vessel and tap to the Tygon tubing are opened to vacuum and evacuated to remove air from the Tygon tubing up to the plastic clip. The side-arm valve to the Tygon tubing is closed. The plastic clip on the foil bag is removed and the sample enters the tubing to the tap. The 


\section{L Bryant et al.}

hydrolysis vessel is isolated from the vacuum line by closing the valves that were opened to the vacuum pump. The side-arm valve is then opened to allow sample from the foil bag into the hydrolysis vessel. The balance is used to measure the weight of sample transferred to the vessel. For the seawater samples and associated standards, $130-150 \mathrm{~mL}$ volumes were transferred to the hydrolysis vessel. The weight of sample is recorded and the sample volume is also measured after hydrolysis (by subtracting the volume of phosphoric acid used). The side-arm valve is closed and the connector tubing removed from the vessel. The He gas cylinder is opened at the regulator and the pressure controlled via a needle valve, so that there is a slight positive pressure of He gas escaping from the attached tubing, which is then connected to the side-arm connector on the reaction vessel. Ten $\mathrm{mL}$ of $85 \%$ orthophosphoric acid (Fischer, Analytical Grade) is added via the dropper funnel to the sample, by slowly opening the tap to the hydrolysis vessel, leaving a small volume $(1 \mathrm{~mL})$ of acid in the funnel and shutting the valve from the funnel to the vessel. The liquid inside the reaction vessel may bubble violently as the $\mathrm{CO}_{2}$ is evolved. The valves from the reaction vessel to the vacuum line are opened and the evolved gas allowed to expand, initially through 2 dry ice-ethanol cryogenic traps, followed by 2 liquid nitrogen traps to cryogenically isolate the evolved $\mathrm{CO}_{2}$. There should be little or no non-condensable gas present, but the vacuum line is finally opened to the vacuum pump, using the valves after the cryogenic traps. The reaction vessel valve is then closed and a further $10 \mathrm{~mL}$ of phosphoric acid is added, as before, to ensure that there is excess acid in the reaction vessel (for seawater the volume of acid added far exceeds the stoichiometric amount required). The process of cryogenic isolation of $\mathrm{CO}_{2}$ is repeated. The side-arm tap is opened to bubble He gas via the glass nozzle, through the sample-acid mixture and the hydrolysis vessel opened to the vacuum line and cryogenic traps, until a pressure of $300 \mathrm{mbar}$ is reached. The vacuum line is opened to a diaphragm pump beyond the cryogenic traps and a pressure of $\sim 250$ mbar is maintained for 5 min to ensure that all dissolved $\mathrm{CO}_{2}$ in the sample/acid mixture has been collected. The tap to the diaphragm pump tap is then fully opened, the He gas shut off, and the side-arm tap to the He closed. Once the pressure gauge reads below 150 mbar, the diaphragm pump is isolated and the vacuum line evacuated with the low-vacuum pump to about $1 \times 10^{-2} \mathrm{mbar}$. The reaction vessel and flexi-tube taps are shut and the water traps isolated, before opening the vacuum line to the high vacuum. The $\mathrm{CO}_{2}$ is then transferred to standard volumes and separated into aliquots for graphitizing and $\delta^{13} \mathrm{C}$ analysis using routine methods.

\section{Testing for Procedural Contamination and/or Foil Bag Contaminants}

He-sparged, boiled deionized water $(500 \mathrm{~mL})$ was added to foil bags under nitrogen and stored for 33 days at $+4{ }^{\circ} \mathrm{C}$ (refrigerated) and $-10{ }^{\circ} \mathrm{C}$ (frozen). Aliquots (130-150 mL) of stored refrigerated water and frozen water (defrosted overnight at $+4{ }^{\circ} \mathrm{C}$ ) were added to evacuated hydrolysis vessels as described previously. The hydrolysis vessels contained IAEA-C2 carbonate (22-28 mg, in order to produce comparable $\mathrm{CO}_{2}$ volumes to the seawater samples), with a consensus value of $7135 \pm 6$ ${ }^{14} \mathrm{C}$ yr BP (Rozanski et al. 1992), chosen to indicate possible modern or infinitely old contaminants in the seawater sample ages, which had expected ages of $<7000{ }^{14} \mathrm{C}$ yr BP.

\section{${ }^{14} \mathrm{C}$ and $\delta^{13} \mathrm{C}$ Analysis}

$\mathrm{CO}_{2}$ from the samples and process standards were separated into isotopically homogenous subsamples of $\mathrm{CO}_{2}$ for graphitization by Fe/Zn reduction (Slota et al. 1987) and ${ }^{14} \mathrm{C}$ analysis, and for $\delta^{13} \mathrm{C}$ analysis. All replicates were analyzed for $\delta^{13} \mathrm{C}$ and some were then selected for ${ }^{14} \mathrm{C}$ analysis. Stable carbon isotope measurements were carried out on a dual-inlet stable isotope mass spectrometer (Thermo Fisher DELTA V Plus), calibrated with international standards and reported as $\delta^{13} \mathrm{C} \%$ relative to Vienna Pee Dee belemnite (VPDB). ${ }^{14} \mathrm{C}$ analysis was performed at the SUERC AMS Laboratory using the $250 \mathrm{keV}$ Single Stage Accelerator Mass Spectrometer (National Electrostatics Corporation; Freeman et al. 2010). The ${ }^{14} \mathrm{C}$ data are reported as $\Delta^{14} \mathrm{C}$, i.e. as per mil deviation from the 


\section{Storage \& Hydrolysis of Seawater for Inorganic C Analysis}

AD 1950 decay-corrected NBS oxalic acid standard (Stuiver and Polach 1977). Background corrections to all ${ }^{14} \mathrm{C}$ data were applied using ${ }^{14} \mathrm{C}$ values from graphites prepared from hydrolyzed, boiled, He-sparged, deionized water added to Iceland spar calcite ( 20 mg) in the hydrolysis vessels.

\section{RESULTS AND DISCUSSION}

There was no significant difference between mean $\delta^{13} \mathrm{C}$ or ${ }^{14} \mathrm{C}$ results for IAEA-C2 to which deionized water, stored frozen or refrigerated for 33 days in foil bags, had been added (Table 1). All individual ${ }^{14} \mathrm{C}$ results were in agreement with the consensus value of $7135 \pm 6{ }^{14} \mathrm{C}$ yr BP (Rozanski et al. 1992) within $2 \sigma$ confidence limits. The carbon contents were as expected for yields from the carbonate standard. There did not appear to be any contamination affecting $\delta^{13} \mathrm{C}$ or ${ }^{14} \mathrm{C}$ from the foil bag components.

Table $1 \delta^{13} \mathrm{C}$ and ${ }^{14} \mathrm{C}$ results of process standards IAEA-C2 hydrolyzed with deionized water stored in foil bags.

\begin{tabular}{llll}
\hline & Mean $1 \sigma \% \mathrm{C}$ by & Mean $1 \sigma$ & mean $1 \sigma$ \\
Storage method of He-sparged, deionized water & weight of IAEA-C2 & ${ }^{14} \mathrm{C}$ yr BP & $\delta^{13} \mathrm{C}_{\text {VPDB }} \%$ \\
\hline Frozen 33 days $(n=2)$ & $11.6 \pm 0.1$ & $7154 \pm 66$ & $-8.3 \pm 0.1$ \\
Refrigerated 33 days $(n=2)$ & $11.7 \pm 0.2$ & $7109 \pm 4$ & $-8.4 \pm 0.1$ \\
Consensus value of IAEA-C2 (Rozanski et al. 1992) & & $7135 \pm 6$ & \\
\hline
\end{tabular}

Stable carbon isotope values for Elie Ness seawater samples ranged from 0.86 to $0.27 \delta^{13} \mathrm{C}_{\mathrm{VPDB}} \%$ (Table 2, Figure 2) over the 33-d storage time. The sample hydrolyzed in the field, i.e. not stored, had the highest $\delta^{13} \mathrm{C}$ value, followed by a decrease to a mean of $0.65 \pm 0.01 \delta^{13} \mathrm{C}_{\mathrm{VPDB}} \%$ for the day 1 refrigerated foil bag samples. This could indicate a storage-related change and would be consistent with ongoing respiration producing $\mathrm{CO}_{2}$ with lower $\delta^{13} \mathrm{C}$. For the refrigerated samples, storage times of 8-33 days showed more scatter between replicates for a given storage time than the $0.21 \%$ difference between the field-hydrolyzed sample and the day 1 foil bag samples. Across all storage times, mean $\delta^{13} \mathrm{C}_{\mathrm{VPDB}} \%$ values for foil bag samples were $0.54 \pm 0.15 \%$ o $(n=12)$ for refrigerated samples and $0.62 \pm 0.03 \%$ o $(n=6)$ for frozen samples. There was no significant difference ( $t$ test, $p<0.01$ ) between refrigerated and frozen $\delta^{13} \mathrm{C}$ values, but refrigerated results were more variable. $\Sigma \mathrm{CO}_{2}$ concentrations across all storage times and methods were $1.961-2.206 \mathrm{mmol} \mathrm{\textrm {kg } ^ { - 1 }}$ (Table 2, Figure 3) and there was no significant difference between mean concentrations in mmol $\mathrm{kg}^{-1}$ for refrigerated samples (2.099 $\left.\pm 0.077, n=12\right)$ and frozen samples $(2.104 \pm 0.047, n=6)$. There was no systematic change in concentration with storage time and no significant relationship with $\delta^{13} \mathrm{C}$ (Figures 3 and 4). The scatter in concentration and $\delta^{13} \mathrm{C}$ values in Elie Ness samples is within the scatter observed by McNichol et al. (1994) for $\Sigma \mathrm{CO}_{2}, 1.50-2.00 \mathrm{mmol} \mathrm{kg}^{-1}(0.5 \mathrm{mmol}$ $\mathrm{kg}^{-1}$ range) and $0.9-1.5 \delta^{13} \mathrm{C}_{\mathrm{VPDB}} \%$ (0.6\% range) in Buzzard Bay seawater samples preserved with mercuric chloride upon collection and stored over 500 days, during which a time series of measurements was made. The scatter in $\Sigma \mathrm{CO}_{2}$ concentrations in the Elie Ness samples is also within the scatter of $\Sigma \mathrm{CO}_{2}$ concentrations (a spread of $16 \mathrm{mg} \mathrm{CO}_{2} \mathrm{~L}^{-1}$ ) for lake-water samples acidified immediately after collection in Exetainers and measured over 160 days of storage (Taipale and Sonninen 2009). During the $160-\mathrm{d}$ storage time, the range of $\delta^{13} \mathrm{C}$ values was $0.6 \%$, also similar to the range observed for stored seawater from Elie Ness and in the storage experiment on Buzzard Bay samples (McNichol et al. 1994). $\Delta^{14} \mathrm{C} \%$ values for all methods and storage times (Table 2, Figure 5) ranged from $79.7 \pm 5.0$ to $90.7 \pm 4.8$ and were indistinguishable within $2 \sigma$ confidence limits. Mean $\pm 1 \sigma$ across all methods and storage times was $83.4 \pm 4.4{ }^{14} \mathrm{C} \%$; mean values for refrigerated samples were $84.6 \pm 4.4 \%$ o $(n=4)$ and for frozen samples $81.0 \pm 1.8 \%$ o $(n=2)$. This scatter is within the uniform uncertainty of $4.5 \%$ recommended for the combined (i.e. large volume radiometric counting and AMS methods) WOCE Pacific Ocean data set (Key et al. 2002). 


\section{L Bryant et al.}

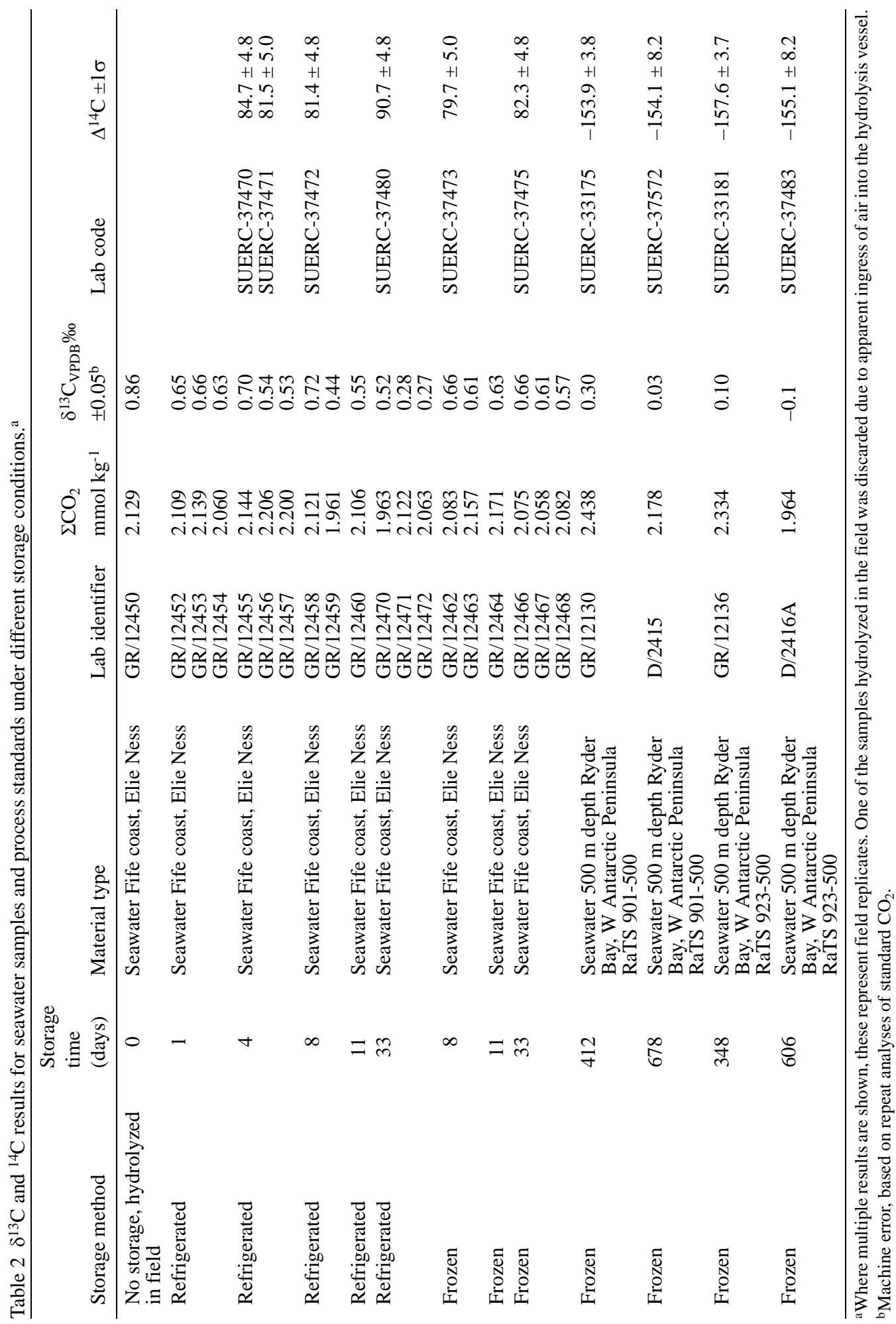




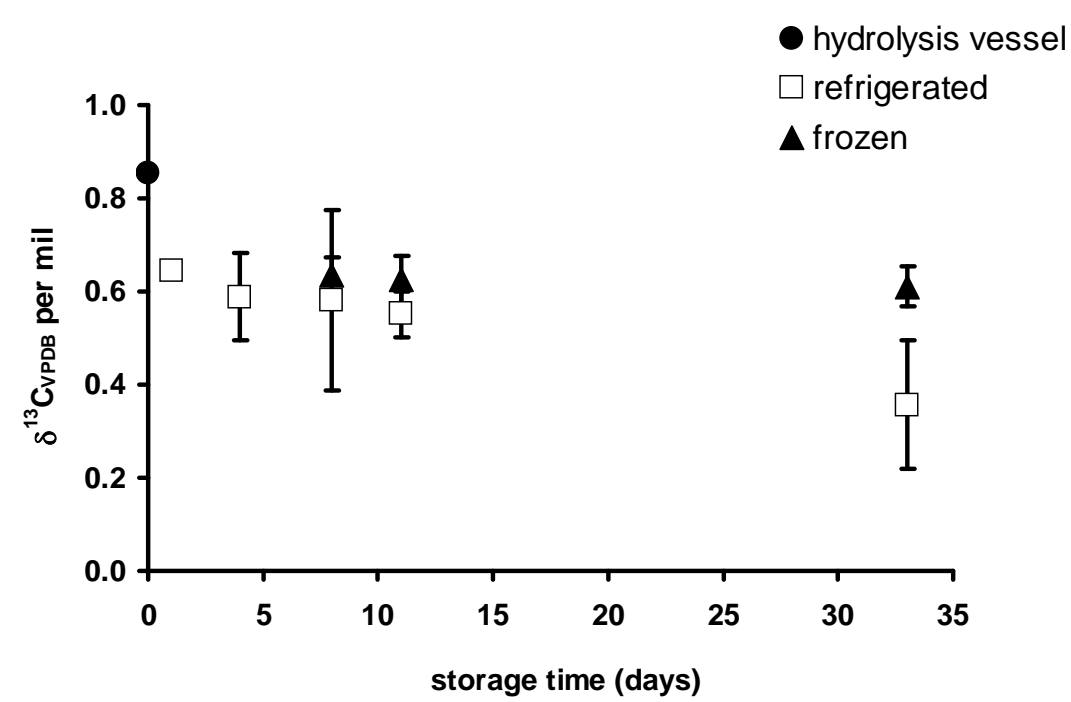

Figure 2 Mean $\delta^{13} \mathrm{C}$ values $( \pm 1 \sigma$ ) for Elie Ness samples hydrolyzed directly after collection in the field, stored in foil bags, refrigerated or frozen. Hydrolysis vessel and day 11 samples are individual measurements only. The error bar for day $1(n=3)$ is less than the symbol height.

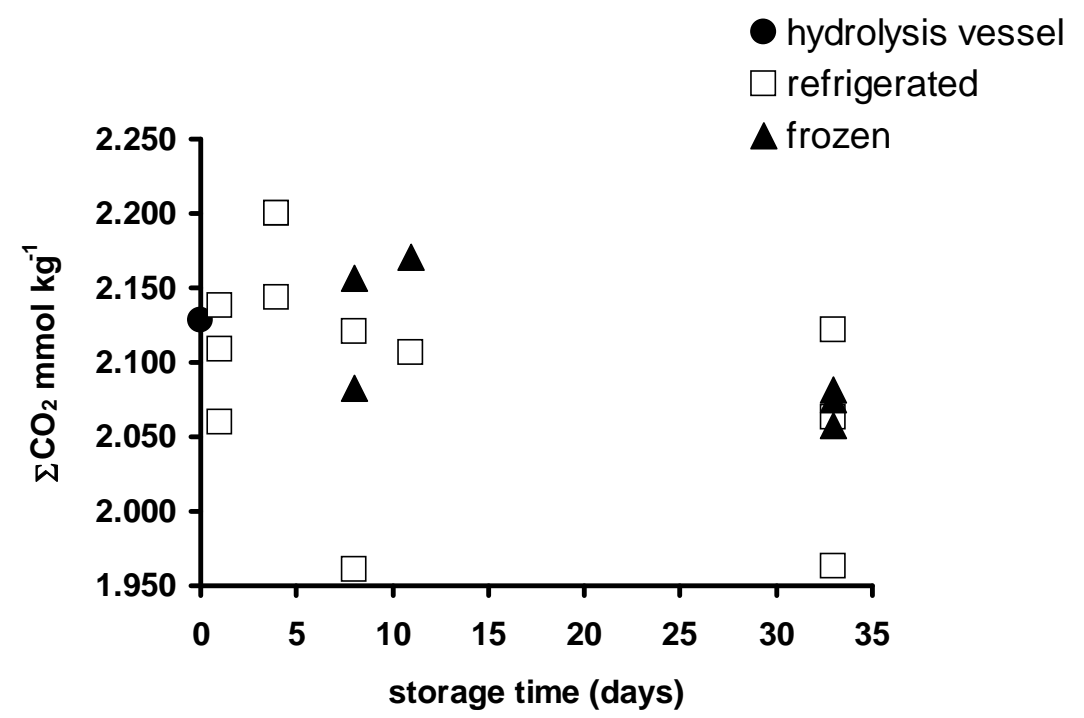

Figure 3 Individual $\Sigma \mathrm{CO}_{2}$ results for Elie Ness samples hydrolyzed directly in the field, or stored refrigerated or frozen in foil bags for different storage times.

Samples from Ryder Bay, western Antarctic Peninsula, showed no significant change in ${ }^{14} \mathrm{C}$ and $\delta^{13} \mathrm{C}$ values (Table 2) following long-term storage, i.e. hydrolysis after defrosting the frozen samples following 11-13 months of storage, and subsequent values after the remaining foil bag sample had been refrozen for a further 10 months, defrosted, and hydrolyzed. Mean $\Delta^{14} \mathrm{C} \%$ values of initial and final hydrolysis were $-154.0 \pm 0.1$ and $-156.4 \pm 1.7$ for the 2 sampling events, respectively, and mean $\delta^{13} \mathrm{C}_{\mathrm{VPDB}} \%$ values were $0.2 \pm 0.2$ and $0.0 \pm 0.1$. While it could be argued that changes had occurred prior to the initial hydrolysis, these results are nonetheless consistent with the data from 
- hydrolysis vessel

$\square$ refrigerated

$\Delta$ frozen

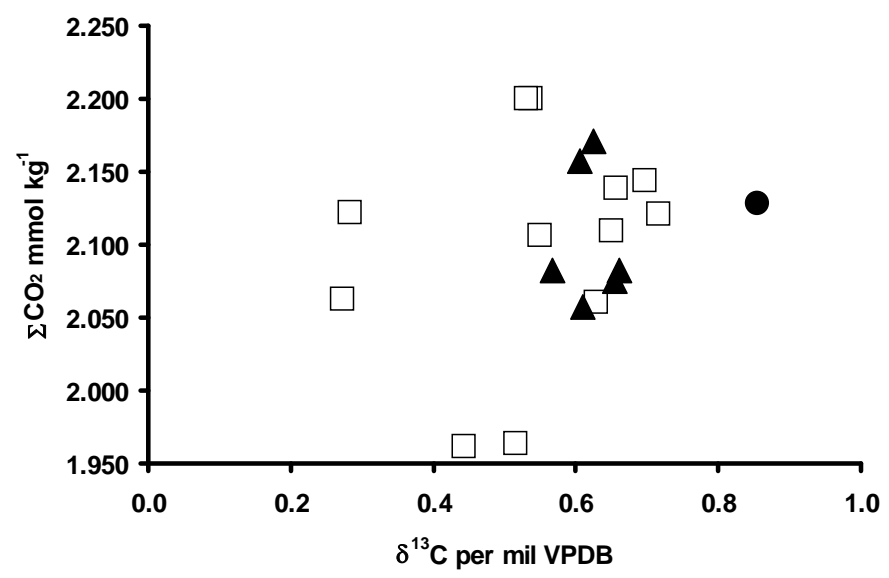

Figure 4 Individual $\Sigma \mathrm{CO}_{2}$ results against $\delta^{13} \mathrm{C}$ values for Elie Ness samples hydrolyzed directly in the field, or stored refrigerated or frozen in foil bags for different storage times.

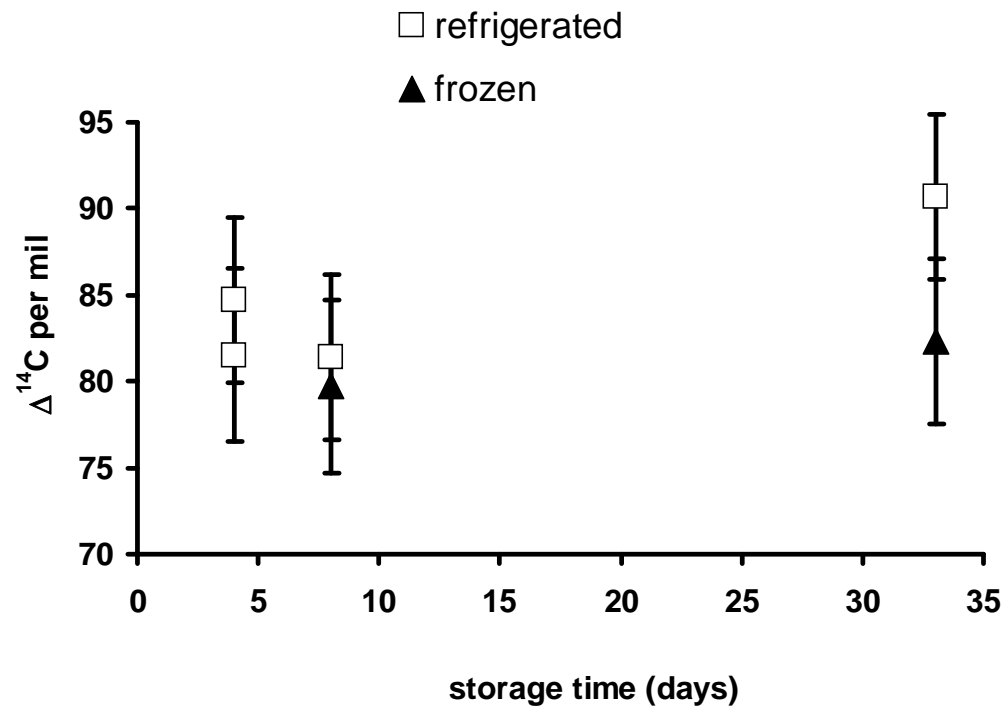

Figure 5 Individual $\Delta^{14} \mathrm{C}$ values $( \pm 1 \sigma)$ for Elie Ness samples stored in foil bags, refrigerated or frozen, for different storage times.

Elie Ness, which showed that freezing the samples in the foil bags does not cause significant ${ }^{14} \mathrm{C}$ or $\delta^{13} \mathrm{C}$ changes in the seawater samples. Furthermore, the Ryder Bay samples indicated that defrosting and refreezing the samples did not change the carbon isotopic composition of the remaining sample in the foil bag. 


\section{CONCLUSION}

Storage of seawater samples in the foil bags was found to be a reliable, alternative method to poisoning for avoiding changes in $\Sigma \mathrm{CO}_{2}, \delta^{13} \mathrm{C}$, and ${ }^{14} \mathrm{C}$ in stored seawater. Freezing samples is recommended for storage beyond a week. The foil bags offer advantages for field sampling, as they are lighter, safer to transport, and similar in cost to glass bottles, and allow sample collection in the field and transfer to the hydrolysis vessel without exposure of the sample to atmosphere, thus reducing the risk of contamination.

\section{ACKNOWLEDGMENTS}

We thank NERC for Facility support and studentship support for SH.

\section{REFERENCES}

Bard E, Arnold M, Maurice P, Duplessy J-C. 1987. Measurements of bomb radiocarbon in the ocean by means of accelerator mass spectrometry: technical aspects. Nuclear Instruments and Methods in Physics Research B 29(1-2):297-301.

Doctor DH, Kendall C, Sebestyen SD, Shanley JB, Ohte N, Boyer EW. 2008. Carbon isotope fractionation of dissolved inorganic carbon (DIC) due to outgassing of carbon dioxide from a headwater stream. Hydrological Processes 22(14):2410-23.

Freeman SPT, Cook GT, Dougans AB, Naysmith P, Wilcken KM, Xu S. 2010. Improved SSAMS performance. Nuclear Instruments and Methods in Physics Research B 268(7-8):715-7.

Garnett MH, Hardie SML, Murray C. 2012. Radiocarbon analysis of methane emitted from the surface of a raised peat bog. Soil Biology \& Biochemistry 50:15863.

Key RM, Quay PD, Schlosser P, McNichol AP, von Reden KF, Schneider RJ, Elder KL, Stuiver M, Göte Östlund H. 2002. WOCE Radiocarbon IV: Pacific Ocean results; P10, P13N, P14C, P18, P19 \& S4P. Ra- diocarbon 44(1):239-92.

Rozanski K, Stichler W, Gonfiantini R, Scott EM, Beukens RP, Kromer B, van der Plicht J. 1992. The IAEA ${ }^{14} \mathrm{C}$ Intercomparison Exercise 1990. Radiocarbon 34(3):506-19.

McNichol AP, Jones GA, Hutton DL, Gagnon AR. 1994. The rapid preparation of seawater $\Sigma \mathrm{CO}_{2}$ for radiocarbon analysis at the National Ocean Sciences AMS Facility. Radiocarbon 36(2):237-46.

Schlosser P, Pfleiderer C, Kromer B, Levin I, Münnich KO, Bonani G, Suter M, Wölfli W. 1987. Measurement of small volume oceanic ${ }^{14} \mathrm{C}$ samples by accelerator mass spectrometry. Radiocarbon 29(3):347-52.

Slota Jr PJ, Jull AJT, Linick TW, Toolin LJ. 1987. Preparation of small samples for ${ }^{14} \mathrm{C}$ accelerator targets by catalytic reduction of CO. Radiocarbon 29(2):303-6.

Stuiver M, Polach HA. 1977. Discussion: reporting of ${ }^{14} \mathrm{C}$ data. Radiocarbon 19(3):355-63.

Taipale SJ, Sonninen E. 2009. The influence of preservation method and time on the $\delta^{13} \mathrm{C}$ value of dissolved inorganic carbon in water samples. Rapid Communications in Mass Spectrometry 23(16):2507-10. 